\section{Tokophobia: an unreasoning dread of childbirth}

\author{
A series of 26 cases \\ KRISTINA HOFBERG and IAN BROCKINGTON
}

\begin{abstract}
Background Some women dread and avoid childbirth despite desperately wanting a baby. This is called tokophobia.
\end{abstract}

Aims To classify tokophobia for the first time in the medical literature.

Method Twenty-six women noted to have an unreasoning dread of childbirth were interviewed by the same psychiatrist, who was not the treating doctor. A qualitative analysis of these psychiatric interviews was performed.

Results Phobic avoidance of pregnancy may date from adolescence (primary tokophobia), be secondary to a traumatic delivery (secondary tokophobia) or be a symptom of prenatal depression (tokophobia as a symptom of depression). Pregnant women with tokophobia who were refused their choice of delivery method suffered higher rates of psychological morbidity than those who achieved their desired delivery method.

Conclusions Tokophobia is a specific and harrowing condition that needs acknowledging. Close liaison between the obstetrician and the psychiatrist in order to assess the balance between surgical and psychiatric morbidity is imperative with tokophobia.

\section{Declaration of interest None.}

Fear of parturition
(1858) as follows:

"If they are primiparous, the expectation of unknown pain preoccupies them beyond all measure, and throws them into a state of inexpressible anxiety. If they are already mothers, they are terrified of the memory of the past and the prospect of the future."

It is well known that pregnancy may be a time of considerable anxiety, with symptoms escalating in the third trimester (Lubin et al, 1975). Women in the 1990s still suffer from the fear of death during delivery (Fava et al, 1990). When this specific anxiety or fear of death during parturition precedes pregnancy and is so intense that tokos ('childbirth') is avoided whenever possible, it is a phobic state called 'tokophobia'.

\section{METHOD}

Subjects for the study were referred from two sources, obstetricians in the West Midlands and psychiatrists on the mother and baby unit (MBU) at the Queen Elizabeth Psychiatric Hospital in Birmingham.

Twenty-seven women were referred for the study, one declined to be interviewed. The remaining 26 women were seen over a two-year period in their homes by the same psychiatrist, who was not the treating doctor. No structured interview was used in this preliminary study. The authors developed an interview that combined narrative histories with specific direct questions for obtaining information. The authors were investigating trends in presentation and past history that may identify women with

tokophobia. They were not investigating an already-established illness pattern. Direct questions were used to elucidate diagnoses of depressive episodes, anxiety disorders and post-traumatic stress disorder (PTSD) using ICD-10 (World Health Organization, 1992). Detailed enquiries were made about the obstetric history, including all pregnancies, contraceptive methods and sexual relationships. The relationship with each baby was examined. Questions about childhood sexual abuse and rape were investigated.

\section{RESULTS}

Twelve women were referred by obstetricians, while 14 were new referrals to the MBU. One was contacted after her story appeared in a magazine. Of the 26 women included in the study, 24 women were married and 24 had had all their children with the same partner. The average age at the time of interview was 33 years (range 22-41). Twenty-five of the subjects had children with no evident disability.

\section{Primary tokophobia}

Eight women in the sample had a dread of childbirth that pre-dated pregnancy, that is, primary tokophobia. The dread of childbirth started in adolescence. Sexual relationships were normal but contraceptive use was scrupulous, some of these women using several methods of protection. Four of the eight women planned their pregnancies despite their intense fears. Two had an overwhelming desire to be a mother and saw that role as their raison d'être. These feelings overpowered their avoidance but did not allay their fear.

One woman conceived only after she had arranged a lower segment Caesarean section (LSCS) for the delivery of her first baby. Most women strongly desired an elective LSCS. Maternal morbidity was evident during these pregnancies (see Table 1).

Table I Events during pregnancy in eight women with primary tokophobia (number of women developing each event type)

\begin{tabular}{cccccc} 
Hyperemesis gravidarum & Anxiety & Prenatal depression & Demanded LSCS & Achieved elective LSCS \\
\hline 5 & 8 & 4 & 4 & 2 \\
\hline
\end{tabular}

LSCS, lower segment Caesarean section. 
Table 3 Events in subsequent pregnancy of 13 women with secondary tokophobia (number of women for each event type)

\begin{tabular}{lcccc}
\hline Depression & Hyperemesis gravidarum & Desired LSCS & Arranged elective LSCS \\
\hline 5 & 5 & 13 & $\mathrm{II}$ \\
\hline
\end{tabular}

LSCS, lower segment Caesarean section.

\section{Outcome of primary tokophobia pregnancies}

Four women achieved their ideal delivery, bonded well with their babies and enjoyed excellent psychological health. Three women endured vaginal deliveries against their will; all three suffered postnatal depression, two suffered symptoms of PTSD and two had delayed bonding with their infants. One woman chose to deliver vaginally despite her intense fears (she was also terrified of needles, hospitals and doctors). She had an emergency LSCS, and suffered postnatal depression.

\section{Secondary tokophobia}

Secondary tokophobia occurs after a traumatic or distressing delivery. Fourteen women in the sample had developed a dread of childbirth after a previous delivery. Ten had experienced instrumental or operative deliveries for foetal distress; two others had suffered severe pain and perineal tearing. Twelve stated that during the delivery they believed that they would die or that the baby had already died. Maternal morbidity was evident and undetected for many months in ten women (see Table 2). One woman who accidentally conceived again organised a termination of pregnancy rather than face another delivery. The dilemma for these women was that the family felt incomplete but the women were terrified of a further delivery.

Nevertheless, 13 of these women proceeded with further pregnancies. Eight were planned where a sibling was wanted for the first baby. Two women suffered miscarriages (before going on to complete a pregnancy to term) and one had an ectopic pregnancy; all three felt enormous relief when these pregnancies did not result in delivery. All 13 women were extremely anxious during their pregnancies with the recurrent, intrusive belief that they were unable to deliver their babies (see Table 3 ).

Eleven women were seen in the postnatal period; two were still pregnant but had arranged an LSCS (see Table 4). Nine of the postnatal women arranged an LSCS, all felt that they had avoided the fearful situation of tokos. Two women had not obtained an operative delivery: one had had a successful vaginal delivery and good psychological outcome, although she retained residual symptoms of PTSD from her first delivery; the other suffered postnatal depression, PTSD and a bonding disorder with her baby. One woman was separated at birth from her baby, who was ill. She suffered bonding delay.

\section{Tokophobia as a symptom of depression}

Four women developed a phobic dread and avoidance of tokos as a symptom of depression in the prenatal period. In each woman this was characterised by a recurrent intrusive belief that she was unable to deliver her baby and, if made to, would die. Of these four women, the first two were primiparous; both felt shocked at the realisation of pregnancy and both became depressed. One sought a termination of pregnancy even though the pregnancy was planned. The other began to exercise strenuously in the hope of inducing a miscarriage rather than endure a vaginal delivery. Both were treated psychologically and recovered spontaneously in the middle trimester of pregnancy. The second two women already had children; both had experienced vaginal deliveries that they perceived as untraumatic. Both of these subsequent pregnancies were planned. In the context of relationship difficulties and depressive illness both women failed to bond with their foetus and became adamant that they could not deliver their babies. The care shown in previous pregnancies was lacking. One woman responded well to antidepressants in the prenatal period and arranged an LSCS. She bonded well with her baby and

Table 2 Psychological morbidity in 14 postnatal women who developed secondary tokophobia after the index pregnancy (number of women presenting each symptom)

\begin{tabular}{lccccc}
\hline Prenatal depression & Postnatal depression & PTSD symptoms & Reduced libido & Bonding delay \\
\hline 0 & 9 & 9 & 12 & 6 \\
\hline
\end{tabular}

PTSD, post-traumatic stress disorder. had no further episode of depression. The second woman declined antidepressant medication in pregnancy and was refused an LSCS. She described a traumatic vaginal delivery, with continued depression postnatally and a feeling of detachment from her baby.

\section{DISCUSSION}

\section{Tokophobia and childhood sexual} abuse

Five women from our sample described a history of childhood sexual abuse and three a traumatic rape. A history of sexual assault may be associated with an aversion to routine obstetric care associated with primary tokophobia or tokophobia as a symptom of depression. The trauma of a vaginal delivery may cause a resurgence of memories of childhood sexual abuse and contribute to secondary tokophobia.

\section{Tokophobia and termination of pregnancy}

Two women in the study terminated a pregnancy because they could not face a delivery. In both cases the baby was much wanted. Another woman described how she was offered a termination of pregnancy when she had begged for an LSCS. A proportion of termination of pregnancies may be requested by women who suffer from tokophobia and want a baby but cannot understand their own strong aversion to parturition. In the absence of an empathic professional listener or relevant medical literature, their only choice may be to terminate the pregnancy.

Table 4 Postnatal events in II women with secondary tokophobia (number of women for each event type)

\begin{tabular}{lccc}
\hline $\begin{array}{l}\text { Delayed } \\
\text { bonding }\end{array}$ & $\begin{array}{c}\text { Postnatal } \\
\text { depression }\end{array}$ & PTSD & $\begin{array}{c}\text { Permanent } \\
\text { contraception }\end{array}$ \\
\hline 2 & 3 & 1 & 10 \\
\hline PTSD, post-traumatic stress disorder &
\end{tabular}

PTSD, post-traumatic stress disorder. 


\section{Tokophobia and hyperemesis gravidarum}

In this study, women with tokophobia had a high rate of hyperemesis gravidarum $(5 / 8$ of those with primary tokophobia, 5/14 of those with secondary tokophobia). A psychological component to hyperemesis gravidarum has been postulated. This may be relevant to tokophobia, when rejection of pregnancy, failure to bond with the foetus, attempts to obtain a termination of pregnancy and terror at an impending delivery may occur.

\section{Tokophobia and PTSD}

PTSD is increasingly being recognised as a consequence of childbirth (Ryding et al, 1997). Among subjects with tokophobia the incidence of PTSD was high, and was associated with traumatic delivery (secondary tokophobia) and denial of the delivery method of choice (primary tokophobia).

\section{Tokophobia and depression}

In this sample depression was a frequent cause and consequence of morbidity. Postnatal depression was associated with refusal of the delivery method of choice and with traumatic and distressing deliveries.

\section{Tokophobia and sterilisation or vasectomy}

Ten women in the sample had completed a sterilisation or were on a waiting list for either sterilisation or vasectomy for their partner, this proportion of couples seeking permanent contraceptive methods shows that they are over-represented in this sample. Ekblad (1961) addressed the issue of 'fear of pregnancy' as a reason for requesting sterilisation. Some childless women presenting for sterilisation may be tokophobic and respond to a psychological approach to dealing with the phobia.

\section{CLINICAL IMPLICATIONS}

- Tokophobia is a distressing psychological disorder that may be overlooked.

- Tokophobia is associated with anxiety, depression, post-traumatic stress disorder and bonding disorders.

Recognition of tokophobia and close liaison with obstetricians may reduce the morbidity associated with tokophobia.

\section{LIMITATIONS}

- The sample size was small.

All the women were Caucasian with English as their first language. They were all in enduring relationships. They are not representative of the population.

No standardised questionnaire was used in this preliminary study.

KRISTINA HOFBERG, MRCPsych, Queen Elizabeth Psychiatric Hospital, Birmingham; I. F. BROCKINGTON, FRCP, Department of Psychiatry, University of Birmingham

Correspondence: Dr K. Hofberg, Department of Psychiatry, University of Birmingham, Queen Elizabeth Psychiatric Hospital, Mindelsohn Way, Birmingham BI5 2QZ; e-mail: kristina. hofberg@virgin.net

(First received 30 November 1998, final revision 15 June 1999, accepted 16 June 1999)

\section{ACKNOWLEDGEMENTS}

We thank Simon Jenkinson for his assistance, and the women in the study for their interest and confidences.

\section{REFERENCES}

Ekblad, M. (1961) The prognosis after sterilization on social-psychiatric grounds. A follow-up study on 225 women. Acta Psychiatrica Scandinavica, 37 (suppl. 16I), $9-162$

Fava, G. A., Grandi, S., Michelacci, L., et al (1990) Hypochondriacal fears and beliefs in pregnancy. Acta Psychiatrica Scandinavica, 82, 70-72.
Lubin, B., Gardiner, S. H. \& Roth, A. (1975) Mood and somatic symptoms during pregnancy. Psychosomatic Medicine, 37, 136-146.

Marce, L. V. (1858) Traite de la Folie des Femmes Enceintes, des Nouvelles Accouchees et des Nourrices. Paris: Baillière.

Ryding, E. L., Wijma, B. \& Wijma, K. (1997) Posttraumatic stress reactions after emergency cesarean section. Acta Obstetrica et Gynecologica Scandinavica, 76 856-861.

World Health Organization (1992) The Tenth Revision of the International Classification of Diseases and Related Health Problems (ICD-10). Geneva: WHO. 